\title{
Lab-scale evaluation of possible mercury speciation in flue gas and mercury emission from combustion of pulverised solid fuels
}

\author{
Maciej Cholewiński ${ }^{1, *}$, Wiesław Rybak $^{1}$ \\ ${ }^{1}$ Wrocław University of Science and Technology, The Faculty of Mechanical and Power Engineering, \\ The Chair of Energy Technologies, Turbines and Modelling of Thermal and Fluid Flow Processes, \\ 50-370 Wrocław, Wybrzeże Wyspiańskiego 27, Poland
}

\begin{abstract}
In this work a new lab-scale method dedicated to the evaluation of both concentration and oxidation level of mercury in flue gases from pulverised fuel fired boiler was proposed. To detect the abovementioned parameters, 2 main steps need to be evaluated. Firstly, a calorimeter bomb is utilised - by a proper implementation of mass balance of mercury within substrates and products, the quantity of oxidised mercury in gaseous products can be evaluated. Then, to simulate solid fuel fired power unit and to calculate mercury concentrations in flue gases, one of the stoichiometric mathematical models of combustion process must be applied. Early validation of the method showed considerable differences between solid fuels in mercury oxidation efficiencies and concentrations in flue gasses. Four examined fuels (lignite, hard coal and 2 types of solid biomass) was investigated. Calculated mercury concentrations in raw flue gas $\left(>700^{\circ} \mathrm{C}\right)$ varied between 4 and $75 \mu \mathrm{g} / \mathrm{m}^{3}$ ref. The lowest quantity of oxidised forms of $\mathrm{Hg}$ in flue gases were identified in the case of investigated lignite $(27 \%$ of total $\mathrm{Hg}$ ), while significantly higher - for selected hard coal (72\%) and one type of biomass (with high chlorine concentration; up to $98 \%$ ).
\end{abstract}

\section{Introduction}

Mercury, a chemical element with an extremely negative impact on living organisms, has been finally classified by the European Union as a dangerous industrial pollutant and, as a result, included into the pro-environmental EU energy policy. This fact becomes particularly important in the Polish power sector, where several new atmospheric emission standards (i.a. Directive 2010/75/EU) will affect significantly the economy of coal-based both electricity and heat generation activities in next few years. Due to the mercury occurrence in hard coals, lignites $(50-1,000 \mathrm{ppb}$ in dry state) and alternative solid fuels (30$3,000 \mathrm{ppb}$ ), as well as to its specific physicochemical transformations during combustion process, the element is released from combustion chamber mainly in gaseous forms. As a result, unlike other pollutants classified as dangerous heavy metals, it must be captured within flue gas duct. This fact has been reflected in the technical guidelines dedicated to

${ }^{*}$ Corresponding author: maciej.cholewinski@pwr.edu.pl 
large combustion plants (both new and existing), which are obligated to meet the future mercury emission levels of $1-10 \mu \mathrm{g} / \mathrm{m}^{3}$ ref starting from the 18th August 2021 (the range of total mercury concentration in flue gases released from combustion chamber varies between $1-100 \mu \mathrm{g} / \mathrm{m}_{\text {ref }}^{3}$ ) [4-5].

As highlighted in the literature [1-4, 6-8], mercury removal within different flue gas treatment technologies depends on mercury speciation, defined as a coexistence of 3 different forms: elemental $\mathrm{Hg}^{0}$ (water-insoluble, poorly reactive), oxidised $\mathrm{Hg}^{2+}$ (watersoluble, reactive) and particle-bounded $\mathrm{Hg}_{\mathrm{p}}$. Understandably, the more gaseous mercury occurs in oxidised forms or is adsorbed on fly ash or slag, the more quantity of mercury can be captured in currently widely used: wet scrubbers (i.a. wet flue gas desulphurisation units - WFGD) and dust collectors (electrostatic precipitators - ESP - or bag filters - FF) [1-3]. While mercury speciation is affected by the composition of solid fuel, combustion working parameters of combustion chamber and pollutant control devices, the economy of mercury capture depends significantly on the type of fuel used in power plant [6-7]. Thus, it is reasonable to identify both cost-effective pollution control devices and fuels that promote high mercury oxidation in flue gases when implemented in power plant.

Unfortunately, extremely complex phenomena and transformations of mercury during the combustion process result in considerable limitations in a proper determination of $\mathrm{Hg}$ oxidation level without direct measurement in real combustion power units. Additionally, due to the sophisticated impact of fuel composition on mercury transformations in flue gas, every mercury-related assessment in solid fuel power plant must be analysed individually $[3-4,8]$. Therefore, to reduce total costs of mercury assessments, it appears to be justified to support them by an application of reliable, validated mathematical and/or laboratory instruments that accurately reflects mercury behaviour and phenomena that occur in existing power systems - including the individual properties of the fuel and combustion technology. In this paper one of the methods dedicated to assessing possible mercury releases and emission rates from pulverised solid fuel fired power unit is proposed. To prove its functionality and prove the existence of substantial differences in mercury oxidation for different solid fuels, the first results for 4 materials are presented as well.

\section{Materials and methods}

The proposed methodology of the investigation possible mercury oxidation level in flue gases is based on selected laboratory tests combined with the mathematical model of the pulverised coal combustion chamber. The simplified algorithm of the procedure is presented in Fig. 1., while the methodology employed in all presented tests is listed below.

The laboratory procedure starts with a proper selection of representative sample of solid fuel from a fuel depot. Then, raw solid material (as received) is milled (to the grain size below $200 \mu \mathrm{m}$ ) and air-dried (surface moisture is calculated on the basis of mass decrease). Next, to evaluate the physicochemical properties of solid fuel for the purpose of further assessments, both proximate (covering the determination of ash (A) and total moisture $\left(\mathrm{W}_{\mathrm{t}}\right)$ contents) and ultimate (carbon $(\mathrm{C})$, hydrogen $(\mathrm{H})$, nitrogen $(\mathrm{N})$, sulphur $(\mathrm{S})$, oxygen $(\mathrm{O})$, chlorine $(\mathrm{Cl})$, mercury $(\mathrm{Hg})$ ones) analysis is conducted. Higher (HHV) and lower (LHV) heating values must be determined as well. It is suggested to conduct all tests on the basis of valid international or Polish (i.a. cited in [4, 9-10]) laboratory standards.

To identify the quantity of mercury that can be oxidised during the combustion process, a laboratory method involving free-standing calorimeter bomb can be utilised. It is based on the combustion of a $1 \mathrm{~g}$ sample of air-dried material in a $350 \mathrm{ml}$ calorimeter bomb filled with $10 \mathrm{ml}$ of deionised water and pure oxygen. After ignition and combustion of the sample, calorimeter bomb is cooled to the ambient temperature, a vessel is degassed and both solid and liquid products are analysed in a reliable, sensitive mercury analyser. The 
level of oxidation of mercury $\left(\mathrm{Hg}_{\mathrm{ex}}\right)$ is determined by calculating the ratio between the mass of element accumulated in deionised water (or, alternatively, $1 \mathrm{M} \mathrm{KCl}$ solution) collected from the bottom of vessel (treated as a total oxidised mercury in products) and the total mass of mercury introduced with substrates.

When fuel is characterised and evaluated under the terms of possible mercury oxidation in flue gases, it is suggested to apply one of the reliable, verified mathematical models of combustion chamber to evaluate the expected $\mathrm{Hg}^{2+}$ concentration in flue gases. In case of pulverised coal-fired power plant, method presented in [1, 4] can be employed. In short, it was based on the stoichiometric calculations including mass balance between substrates $\left(\mathrm{C}, \mathrm{H}, \mathrm{N}, \mathrm{S}, \mathrm{O}, \mathrm{W}_{\mathrm{t}}, \mathrm{Cl}, \mathrm{Hg}\right.$ contents) and products $\left(\mathrm{CO}_{2}, \mathrm{H}_{2} \mathrm{O}, \mathrm{O}_{2}, \mathrm{~N}_{2}, \mathrm{SO}_{2}, \mathrm{HCl}\right.$, $\mathrm{Hg}, \mathrm{A})$, combined with fixed values of: excess air $(\lambda), \mathrm{NO}_{\mathrm{x}}$ concentration and carbon presence in both slag and fly ash. As a result, it is possible to calculate the composition of flue gases at a temperature above $700^{\circ} \mathrm{C}$. A detailed description of the model (including utilised equations) can be found in author's publication [1], which was published in previous volume of EPJ.

\section{PROXIMATE AND ULTIMATE ANALYSIS}

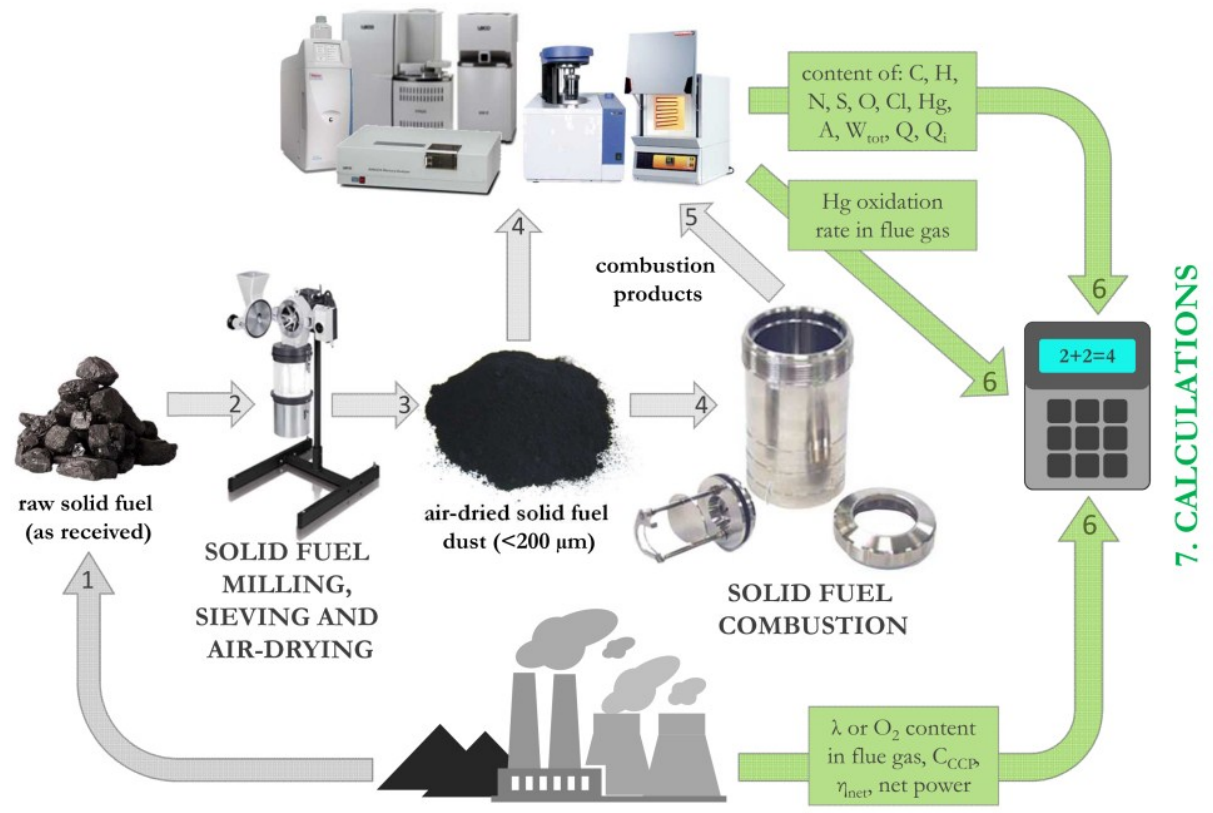

COAL DEPOTS \& SOLID FUEL FIRED POWER UNIT

Fig. 1. The scheme of the lab-scale mercury emission assessment procedure (numbers in the arrowheads present suggested sequence of actions)

To highlight the impact of the type of solid fuel on the efficiency of mercury capture system, 4 different solid fuels (hard coal, lignite and 2 types of biomass) were investigated. To evaluate the physicochemical parameters of solid fuels, laboratory equipment - LECO TruSpec CHNS (AAS-based C, H, N and S analyser), LECO AMA254 (CVAAS-based mercury analyser), Dionex ICS-1100 (IEC; $\mathrm{Cl}$ content was calculated by investigation of the chlorine content in water solution from calorimeter bomb) and IKA C-2000 Basic calorimeter (HHV) were used [4, 9-10]. To identify A and $\mathrm{W}_{\mathrm{t}}$ contents, gravimetric tests according to PN/ISO standards - were employed.

To simulate the formation of mercury speciation after the combustion in calorimeter bomb, the time of 2 min was set to satisfy the proper solid fuel burnout. The calorimeter 
bomb was cooled in a water bath (with the temperature of approx. $15^{\circ} \mathrm{C}$ ) for 5 minutes before degassing. As mentioned before, the quantity of water-soluble mercury detected during the tests with calorimeter bomb represented the fraction of $\mathrm{Hg}^{2+} \& \mathrm{Hg}_{\mathrm{p}}$ (after homogenous, non-catalytic adsorption) possible to capture within all pollution control devices.

\section{Results}

All results are shown in Tab. 1. and Tab. 2. Detected total mercury oxidation level $\left(\mathrm{Hg}_{\mathrm{ox}}\right)$ as well as possible mercury emission $\left(\mathrm{E}_{\mathrm{Hg}}\right)$ and concentrations in flue gases after combustion chamber $\left(\mathrm{U}_{\mathrm{Hg}}\right)$ were shown in Tab. 2.

Table 1. Results of elemental analysis of the selected solid fuels (dry state)

\begin{tabular}{|c|c|c|c|c|c|c|c|}
\hline \multirow{2}{*}{ Fuel } & C & H & $\mathbf{N}$ & $\mathbf{S}$ & $\mathbf{O}$ & Cl & \multirow{2}{*}{$\frac{\mathbf{H g}}{p p b}$} \\
\hline & \multicolumn{6}{|c|}{$\%$} & \\
\hline lignite & 56.50 & 4.05 & 0.59 & 1.24 & 19.83 & 0.02 & 581 \\
\hline hard coal & 78.10 & 4.46 & 1.23 & 1.28 & 5.77 & 0.33 & 75 \\
\hline olive marc & 51.09 & 5.73 & 1.54 & 0.08 & 32.44 & 0.31 & 39 \\
\hline cereal bran & 45.72 & 5.63 & 2.18 & 0.64 & 28.65 & 0.01 & 50 \\
\hline
\end{tabular}

Table 2. Selected proximate properties of the solid fuels and calculated mercury concentrations in both raw and cleaned flue gases

\begin{tabular}{|c|c|c|c|c|c|c|c|}
\hline \multirow{2}{*}{ Fuel } & $\mathbf{H H V}^{\mathbf{d}}$ & $\mathbf{L H V}$ & $\mathbf{A}^{\mathbf{d}}$ & $\mathbf{W}_{\mathbf{t}}^{\mathbf{r}}$ & $\mathbf{H g}_{\mathbf{0}}{ }^{\mathbf{a}}$ & $\mathbf{U}_{\mathbf{H g}}{ }^{\mathbf{1}}$ & $\mathbf{E}_{\mathbf{H g}}^{\mathbf{1 , 2}}$ \\
\cline { 2 - 8 } & \multicolumn{2}{|c|}{$M J / \mathrm{kg}$} & \multicolumn{4}{|c|}{$\%$} & \multicolumn{2}{|c|}{$\mu \mathrm{g} / \mathrm{m}^{3}{ }_{\mathrm{ref}}$} \\
\hline lignite & 21.71 & 20.83 & 17.77 & 49.08 & 26.9 & 77.62 & 52.10 \\
\hline hard coal & 26.56 & 25.58 & 8.84 & 6.61 & 81.2 & 6.92 & 1.43 \\
\hline olive marc & 19.14 & 17.89 & 8.82 & 17.79 & 98.8 & 5.64 & 0.34 \\
\hline cereal bran & 17.58 & 16.35 & 17.16 & 10.48 & 53.9 & 7.92 & 3.48 \\
\hline
\end{tabular}

${ }^{d}$ - dry state, ${ }^{\text {a }}$ - air-dried state, ${ }^{\mathrm{r}}$ - "as received" state, ${ }^{1}$ - in reference conditions $\left(101,325 \mathrm{~Pa}, 237 \mathrm{~K}\right.$, dry, $\mathrm{O}_{2}$ concentration $-6 \%$ ) for excess air $\lambda=1.3$ and the atmosphere of $\mathrm{O}_{2} / \mathrm{N}_{2}=21 / 79,{ }^{2}$ - it was assumed, that $90 \%$ of

both oxidised $\left(\mathrm{Hg}^{2+}\right)$ and particle-bounded mercury $\left(\mathrm{Hg}_{\mathrm{p}}\right)$ is captured in all air protection technologies

It can be easily noted that obtained values reflect the significant differences $(27-99 \%$ of total mercury from substrates) in $\mathrm{Hg}$ oxidation level. That can be explained by the fact of different contents of chlorine, mercury and sulphur in solid fuels. The results obtained on the basis of the described method suggest the mercury releases from combustion chamber $\left(\mathrm{R}_{\mathrm{Hg}}\right)$ at the level of $5-78 \mu \mathrm{g} / \mathrm{m}^{3}$ ref and mercury emission from insignificant 0.3 to the notable value of $52 \mu \mathrm{g} / \mathrm{m}^{3}$ ref. It might be assumed that the less favourable oxidation of mercury in flue gass (see $\mathrm{Cl} / \mathrm{Hg} / \mathrm{S}$ ratios) will occur in the case of lignite, while the most in the case of olive marc. For hard coal, mercury oxidation might be limited by the more significant presence of $\mathrm{SO}_{2}$. Similarly, low chlorine content in cereal bran might result in the decrease of $\mathrm{Hg}^{2+}$ fraction in flue gases.

Importantly, the obtained results seem to prove the common trends concerning mercury oxidation phenomenon in flue gases from combustion units, suggested in several independent full scale tests and measurements [3, 5, 8, 11-12].

All differences in mercury oxidation levels prove the fact, that extremely complex nature of mercury transformations in flue gas should be reflected by the need of individual, precise $\mathrm{Hg}$ assessments (including possible oxidation) for every source of energy. Mercury speciation in flue gas seems to be very sensitive to the specific composition of solid fuel, therefore i.a. the implementation of particular coal or biomass should be preceded by individual lab-studies. For example, the co-combustion of cereal bran with hard coal seems to be less favourable than with olive marc. 


\section{Conclusions}

The procedure presented in this paper, dedicated to pulverised fired power plants, highlights the significant variations in mercury oxidation levels in flue gases from different solid fuels. Therefore, while all cited mercury phenomena appear to be reflected in suggested lab-scale test, it might be considered as one of the promising calculation methods in all mercury-related assessments conducted in all pulverised fuel power plants. When validated and standardised, it would be used to forecast future mercury releases from power sector, to select and adjust the parameters of air protection technologies or to improve all national assessments concerning mercury releases from combustion chambers and power units (by the evaluation of individual emission rates for every solid fuel).

Assuming that all conducted tests represent full scale power unit, it can be noted, that for 3 of 4 examined fuels it would be possible to meet BAT-AELs requirements without the implementation of additional mercury-focused air protection technologies. However, in the case of lignite, the fact of unfavourable mercury concentration and speciation points the need for radical actions towards reducing the mercury concentration in emitted flue gases.

While preliminary results proved the existence of some typical mercury phenomena in both laboratory and full scale units, it is planned to conduct, in the nearest future, several validation procedures in order to obtain further improvements in reliability (including the adsorption of mercury on different fly ashes). It seems to be vital to standardise the methodology concerning the stage with calorimeter bomb as well - in order to identify the most profitable combustion process parameters (i.a. times and solutions).

\section{References}

1. M. Cholewinski. EPJ Web Conf. 177, 01001 (2018)

2. I. Naruse, R. Yoshiie, T. Kameshima, T. Takuwa. J Mater Cycles Waste Manag 12, 154-160 (2010)

3. J. Zhou, Z. Luo, Y. Zhu, M. Fang, Mercury Emission and its Control in Chinese CoalFired Power Plants (Zhejiang University Press and Springer, Hangzhou, 2013)

4. M. Cholewinski. Zeszyty Energetyczne 4, 73-87 (2017) (in Polish)

5. T. Lecomte, J. F. Ferrería de la Fuente, F. Neuwahl, M. Canova, A. Pinasseau, I. Jankov, T. Brinkmann, S. Roudier, L. Delgado Sancho, Best Available Techniques (BAT) Reference Document for Large Combustion Plants (EUR 28836 EN, Joint Research Centre, Sevilla, 2017)

6. J. C. Kramlich, L. Castiglone, The Homogeneous Forcing of Mercury Oxidation to Provide Low-Cost Capture (University of Washington, Seattle, 2009)

7. S. Niksa, J. J. Helbe, N. Fujiwara. Environ. Sci. Technol. 35(18), 3701-3706 (2001)

8. P. Burmistrz, K. Kogut, M. Marczak, J. Zwoździak. Fuel Process. Technol. 152, 250258 (2016)

9. W. Moroń. Zeszyty Energetyczne 2, 31-41 (2015) (in Polish)

10. M. Dudek. Zawartość rtęci w biomasach drugiej generacji (Mercury content in 2nd generation biomass) (Wrocław University of Technology, Wrocław, 2013) (in Polish)

11. R. Spörl, J. Maier, L. Belo, K. Shah, R. Stranger, T. Wall, G. Scheffknecht. Energy Procedia 63, 386-402 (2014)

12. J. Gołaś, A. Strugała, Mercury as a coal combustion pollutant (AGH University of Science and Technology, Warsaw, 2014) 